\title{
Evaluating Innovation and Export Capabilities of SMEs: Toward a Multi-Criteria Decision-Making Methodology
}

\author{
Manon Enjolras ${ }^{1^{*}}$, Mauricio Camargo ${ }^{1}$, Christophe Schmitt ${ }^{2}$
}

\begin{abstract}
A large number of studies have demonstrated the strong influence of and correlation between innovation and export activities as key factors of the firm's competitiveness. However, these two activities have usually been considered independently of each other in terms of management and support. This paper relies on the characterization of a conceptual innovation/export common space representing the synergistic effects between these two activities. A hybrid AHP/Flowsort MCDM-methodology is proposed in order to model this common space through the evaluation of a framework of joint practices related simultaneously to the innovation and export capabilities of SMEs. The relevance of this methodology is tested through the design of a decision-making tool applied to a French exporting and innovative SME. This case study opens up further research perspectives and points to areas for improvement in the evaluation of SMEs' capabilities.
\end{abstract}

Keywords: SMEs; Innovation; Export; Synergies; Multicriteria analysis; Decision-Making; AHP; Flowsort.

Submitted: May 6 $6^{\text {th }}, 2020 /$ Approved: October $22^{\text {nd }}, 2020$

\section{Introduction}

Innovation and export activities have been identified as two of the main drivers of economic growth (Bołkunow, 2019; Pla-Barber and Alegre, 2007). In the specific case of small businesses, innovative SMEs (including product/ process/ service/ organizational and commercial innovation (OECD, 2018)) are more likely to be engaged in global markets than non-innovative firms. A report on the behavior of European SMEs (FedEx corp., 2015) shows that in 2015, fastergrowing SMEs (52\%) were almost twice as likely to export as SMEs that were in decline or static (28\%). At the European level, survey evidence from the European Commission (OECD, 2009) shows that European SMEs which were internationally active were three times more likely to introduce new products or services than their purely domestic counterparts, and that they grew more than twice as fast. And from 2012 to 2014, innovators were more prevalent among exporters than non-exporters, with the gap being widest for product and process innovations. Exporting SMEs introduced twice as many product and process innovations as non-exporting SMEs (European Commission, 2018). Outside Europe, this trend seems to be the same. For example, Canadian SME exporters are significant innovators. In 2011, it was reported that 60 percent of exporters introduced at least one type of innovation (product, process, organizational or marketing) compared with only 35 percent of non-exporters (Seens, 2015). The figures speak for themselves, and it seems that small innovative companies are more present internationally and vice versa.

This observation suggests the existence of a close relationship between innovation and export activities that has been identified both within the scientific literature and among support bodies. Research works studying this link are plentiful (Love and Roper, 2015) and the advantages of coupling support services related to innovation and exports has been detected (European Commission, 2007). Yet, although this link is identified in a theoretical way, in practice institutional support services integrating a joint vision of innovation and exports are rare. This joint vision nonetheless represents an interesting way to manage the complexity of companies and takes on its full importance in the particular context of SMEs, for whom available resources are limited (Szczepanski, 2016).

The objective of this work is to operationalize the relationship between innovation and export through the proposition of an SME support tool. This tool provides a joint vision of firms' innovation and export capabilities and is called PE2I (Potential Exportation and Innovation Index). It relies on a Multi-Criteria Decision-Making (MCDM) methodology to model this relationship through the paradigm of complexity (Kurka and Blackwood, 2013) and to support the decision-making process through a joint evaluation of the innovation and exportation capabilities of SMEs. The main specificity of this tool is its focus on the activities/resources/skills which a SME has to mobilize first and foremost in order to simultaneously improve its innovation and export performances, while reducing the effort associated with this improvement. The index is based on a measure of the firm's maturity in terms of joint innovation/export practices. It enables a diagnosis of the specific situation of a company by identifying its strengths and its weaknesses and gives an indication of its potential orientation (innovation-oriented company and lor export-oriented company). From this current situation, customized means of improvement can be identified and proposed in line with the company's context as well as its development strategy. For example, if the company wishes to favor its development in foreign markets, the PE2I will identify the main levers for it to reach this goal. Alternatively, if

(1) Université de Lorraine, ERPI, F-54000, Nancy, France

(2) Université de Lorraine - CEREFIGE, F-54000, Nancy, France

${ }^{*}$ Corresponding author: manon.enjolras@univ-lorraine.fr

ISSN: 0718-2724. (http://jotmi.org)

Journal of Technology Management \& Innovation (c) Universidad Alberto Hurtado, Facultad de Economía y Negocios. 
the company wishes to move more significantly toward innovation, the PE2I will propose different levers of action. And if the company wishes to set up a common strategy involving both innovation and exports, here again, adapted levers of action will be identified. While the relationship between innovation and exportation has mostly been studied theoretically, this research puts it into practice through the proposal of a pragmatic diagnostic tool, thus contributing to the scientific literature on innovative and exporting SMEs.

The paper will be structured as follows. First, the context of SME innovation and exports will be presented in order to outline how innovation/export coupling can contribute to SME support. Next, the theoretical and methodological foundations of the PE2I will be clarified. Finally, a case study based on the evaluation of an exporting and innovative French SME will be presented.

\section{Literature Review}

\section{Innovation and Export: Toward a vision in terms of complemen- tarities}

The innovation/export relationship in the context of SMEs is a very important research area in the current scientific literature. The dominating paradigm can be qualified as causal, because it puts forward a cause and effect relationship between innovation and exports (Love and Roper, 2015). Innovation would have a positive impact on exports and/or vice versa. Traditionally, two theories coexist: "self-selection" and "learning-by-exporting". The theory of self-selection is based on a hypothesis according to which innovation allows companies to reach the international market more easily (Boso et al., 2013; Dai et al., 2019; Monreal-Pérez et al., 2012; Ribau et al., 2019; Roper and Love, 2002). It confers a competitive advantage upon the company, which allows it to acquire a higher general performance and to improve its resource optimization. Innovation thus allows companies to be more competitive on the overseas markets and facilitates their internationalization. The theory of "Learning-by-exporting" is based on a hypothesis according to which exports lead to an improvement in innovation within a company, as well as its performances more generally (Di Cintio et al., 2019; Fassio, 2018; Golovko and Valentini, 2014; Kafouros et al., 2008). The discovery of an overseas market allows the company to acquire a large quantity of information and knowledge. This acquired knowledge urges the company to adapt and thus to innovate in order to maximize its success both on this new market and on its domestic market. The more widely accepted theory seems to be self-selection, whereby innovation can be considered as a necessary but insufficient condition for SMEs to export. A large number of studies have tested this theory on several types of SME (testing for business sector, geographic area, innovation type - product or process, etc.) and generally, self-selection seems to be valid for SMEs, particularly as regards product innovation. The results on process innovation are debatable, however. Concerning the Learningby-exporting theory, the results of numerous studies seem to be diverse in the particular context of SMEs. They do not seem to reach a real consensus. The current literature highlights a significant link between innovation and exports, putting forward two theories based on a cause and effect relationship. However, in the particular context of SMEs, the results are highly variable from one study to another and they depend on several differentiating factors: business sector, size of the company, temporality, cultural distance from the overseas market and innovation type (product or process).

Based on that, several authors have shown that the causality between innovation and export can be bidirectional. This means that the theories of self-selection and learning-by-exporting could coexist in the form of a virtuous circle (Ayllon and Radicic, 2019; Golovko and Valentini, 2014; Halilem et al., 2014; Zehir et al., 2015). In the case of SMEs, innovation seems to impact positively on export performance (particularly product innovation) and exports also seem to improve the innovation capability of SMEs with a specific temporality. They highlight that selfselection and learning-by-exporting can coexist in the form of a temporal sequence. Other studies go farther and propose an analysis with a slightly different objective. These authors try to show that in the case of SMEs, innovation and exports are complementary: if a commitment is made in one of these activities, it facilitates the commitment in the other one (by reducing costs or increasing profits). The results of Golovko and Valentini (2011) show that Spanish manufacturing SMEs who invest in innovation and export at the same time enjoy better growth than those who invest either in innovation or in exports or in neither. The return on investment of one activity increases with the performance level of the other activity. However, Ayllon and Radicic (2019) found that while a complementarity between innovation and exports exists, it remains only through contemporaneous effects. Their results suggest no support for a causal link from past product and process innovations to current export activities. Based on that, the innovation/export relationship shifts from an impact-related point of view to a complementarity paradigm, including a temporal aspect.

\section{MCDM analysis as a decision support system for SMEs}

Since the 1980s, the main role of MultiCriteria Decision Making analysis has progressed from a multi-objective optimization process to a way of providing decision support to decision-makers. Through the development of Multiple Criteria Decision Support Systems (MCDSS), these support tools aim to capture the decision-maker's choice behavior and the systemic nature of the decision process instead of solving well-structured problems relying on hypothetical assumptions (Korhonen et al., 1992). MCDSS support decision-makers by modelling and structuring a coherent picture of complex decision problems (Kurka and Blackwood, 2013).

Most of the issues that an organization has to manage are complex problems. Innovation and export fall into this category because they can be qualified as "disorganizing" activities that directly affect the value creation process of companies (Torrès and Julien 2005). A lack of formalization of strategy, as well as centralized management in the particular case of SMEs, make it difficult to manage complex situations (Moeuf et al., 2018; Okreglicka et al., 2015; Schmitt et al., 2002). Therefore, it is necessary to support SMEs in their decision-making processes so that they may handle the complexity associated with these processes and facilitate the management of "disorganizing" activities such as innovation and exports. 
In order to identify MCDSS dedicated to innovation and/or export management, a bibliometric analysis was conducted. The main objective of this analysis was to facilitate the examination of a large dataset of publications related to innovation and export MCDSS based on statistical techniques. This quantitative statistical analysis supports the design of a global picture reflecting the state of the art of this research area. More precisely, a keyword occurrence technique was chosen in order to analyze the concepts addressed in the scientific publications as well as their aggregation and relationships.

Using the "Web of Sciences" scientific database, the following criteria were considered:

- Type of documents $=$ research articles

- Language: English
- Publication years: from 2000 to 2020

- Advanced search using the following keyword request: TITLE $=[$ (multicriteria OR "multiple criteria" OR multi-criteria OR decision) AND (innovat* OR export*) AND (assess ${ }^{\star}$ OR method $^{\star}$ OR system ${ }^{\star}$ OR tool ${ }^{\star}$ OR eval $\left.{ }^{\star}\right)$ ]

A total of 102 articles were identified and exploited through the creation of a visualization map representing the occurrence of keywords in publications. Using the software VOSviewer, ${ }^{1}$ an occurrence map was created (Figure 1). This visual representation uses data spatialization to highlight the most frequent occurrences (the bubbles with the largest diameter) as well as the links between the keywords.

Figure 1: Occurrence map (VOSViewer)

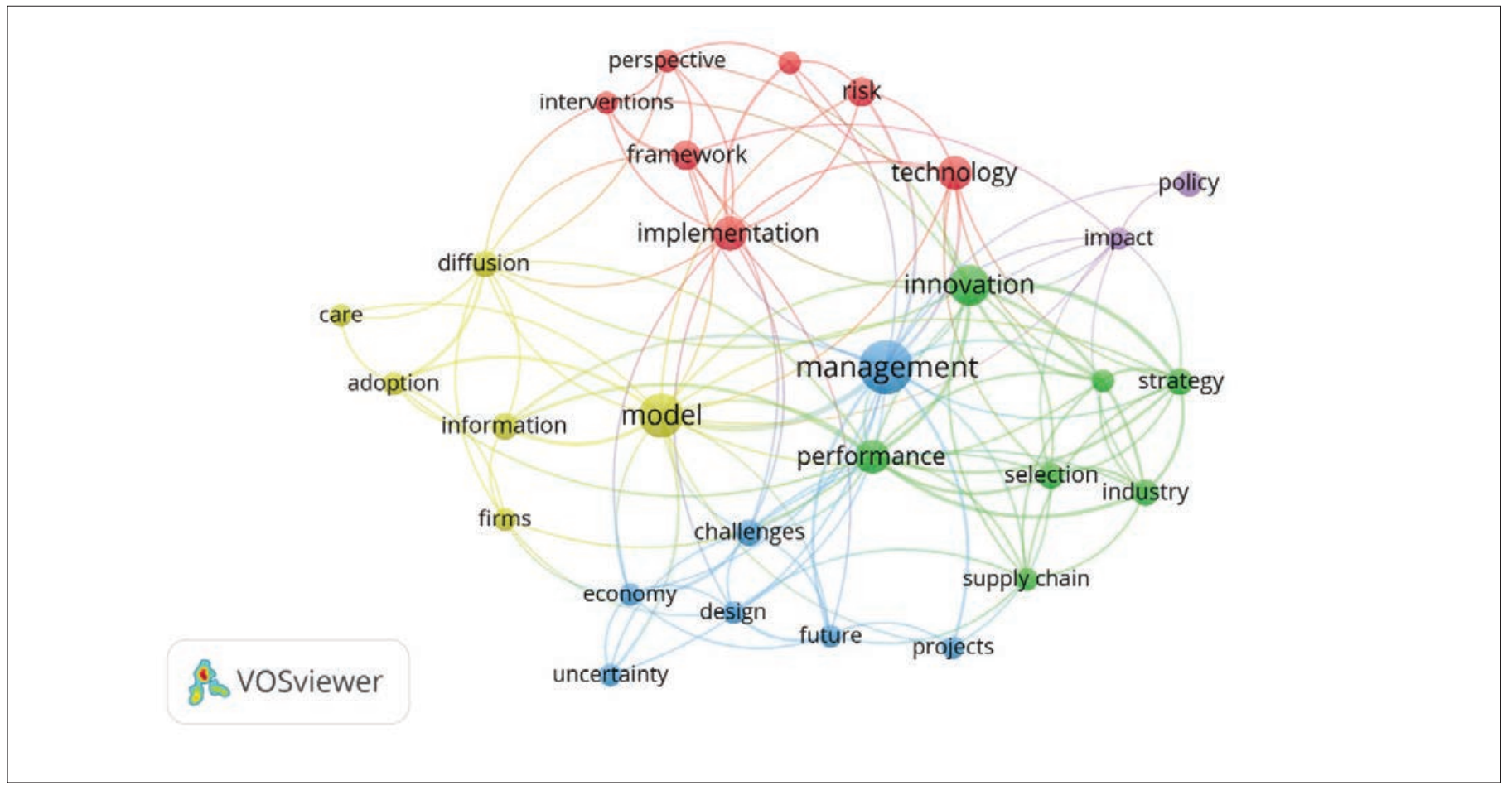

The exploitation of these bibliographic data yields interesting findings on MCDSS in the literature. First, the keyword "export" or any other terms associated with the internationalization process of a firm do not appear on this map. It seems that MCDSS are more commonly used for innovation management. Combining this assumption with a systematic analysis of the publications considered, it appears that the number of articles addressing decision-making on export topics is indeed very low (7 articles out of 102). Moreover, they mostly focus on a global performance assessment (integrating exports) in terms of supply chain management, in particular (Castro Silva et al., 2015; Chiadamrong and Kawtummachai 2008). Therefore, authors agree on the fact that the literature lacks comprehensive and pragmatic frameworks for measuring export performance, even though many success factors have been identified and tested (Dahooie et al. 2020). All the other publications concern decision-making applications related to the innovation process in different contexts.

Coming back to the bibliometric analysis and relying on a simplified $5 \mathrm{~W} 2 \mathrm{H}$ structure ("Who/Where", "What", "Why" and "How") (Table 1 ), it seems that the main MCDSS operate at firm level (mostly in industry), in order to evaluate/ select/ disseminate/ prevent phenomena related to innovation/technology/ performance/ management/ behavior through a decision-making model/ framework/ system or simulation.

(1) http://www.vosviewer.com 
Table 1. Bibliometric data exploitation

\begin{tabular}{cccc}
\hline Who / Where & What & Why & How \\
\hline Firm & Innovation & Evaluation & Model \\
Industry & Technology & Selection & Framework \\
Care & Performance & Impact & Systems \\
Projects & Strategy & Diffusion & Simulation \\
Policy & Management & Prevention & \\
Supply chain & Behavior & Future & \\
& Interventions & Implementation & \\
& Challenges & Perspectives & \\
& Information & Uncertainty & \\
& &
\end{tabular}

In the specific case of the evaluation of SMEs' innovation and export capabilities, the use of MCDSS seems to be in line with the applications found in the literature. MCDSS enable an evaluation (Why) of SMEs' (Who) innovation and export management behavior (What) through a framework embracing a complex vision of innovation and export synergies (How).

\section{Positioning and research objectives}

Based on a change of paradigm initiated in the literature on the innovation/export relationship, this paper suggests an alternative to the analytical vision consisting in handling innovation and exports separately within companies, instead favoring a systemic vision that considers the existing synergies between these two activities. In line with the previous work of Enjolras et al. (2016), the proposed methodology proposes to consider innovation and exports as two complementary activities integrating a common space which can be considered as an interface between these two activities. This common space represents the activities which an SME has to carry out first and foremost in order to simultaneously create value in terms of innovation and exports (Figure 2). In the particular context of SMEs, for whom the lack of resources is a particularly important issue (Szczepanski, 2016), this vision seems to make sense. It is based on the assumption that it is possible to exploit an innovation/export synergy in order to reduce the effort required to achieve a defined objective. By acting in this common space, enterprises potentially trigger a single lever which simultaneously impacts on their innovation and export activities, and produces a synergetic result that requires less effort than two separate actions.

The scientific contribution of this research work therefore lies in the systemic vision chosen to analyze this relationship within SMEs and in the use of MCDM methods to support and model this complex vision, through the proposition of a strategic decision-making tool to support SMEs' development.
Figure 2: A joint innovation/export vision

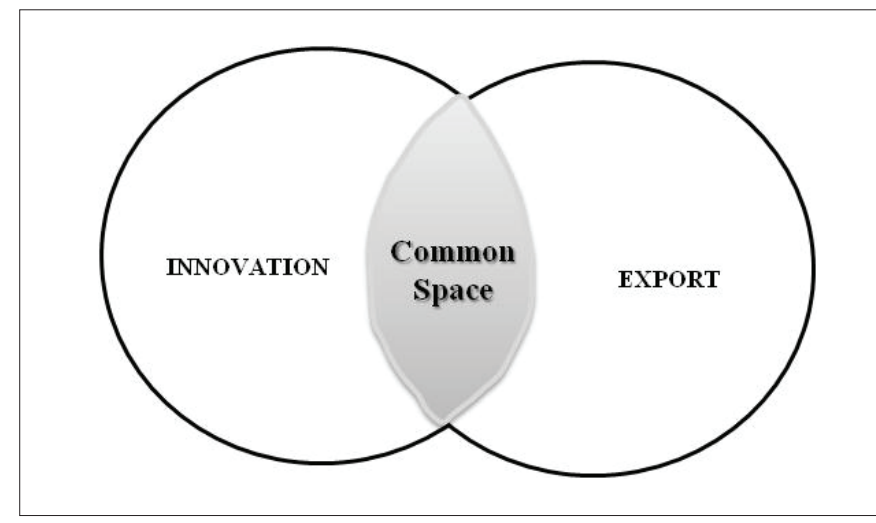

\section{Proposal of a methodology to evaluate SMEs' innovation and export capabilities}

This research presents and tests a decision-making tool intended to estimate SMEs' innovation and export capabilities: the PE2I (Potential Export and Innovation Index). This index proposes a diagnosis of the company's situation based on a complex vision of the innovation/ export relationship. It allows the identification of strengths and weaknesses and proposes means of improvement adapted to the company's strategy: innovation-based, export-led or jointly-oriented.

\section{Theoretical framework and methodological steps}

Although a lot of research has been done on the link between innovation and export, there is little on the operational translation of this link and therefore few common reference frameworks. The existing research mentioning the notion of a common reference framework focuses on the analysis of the innovation / export link in itself. For example, Chen et al. (2018) propose a unified framework to estimate the direct and indirect effects of exporting on firm innovation. In the same vein, Gkypali et al. (2018) propose a unified framework including absorptive capacity, exporting activities, innovation openness and innovation performance, and study the mutual effects of these factors. The common reference system is therefore a means of analysis of the innovation/export relationship and not a representation of this relationship. However, many best practice frameworks exist specifically for innovation in the form of practices, models or processes (Biemans and Griffin, 2018; Boly et al., 2014; Leonidou et al., 2018). On the topic of export, the literature moves away from the notion of practices. Publications propose reference frameworks that focus on barriers, determining factors or drivers of exportation (Angela et al., 2015; Kahiya, 2018; Zhu and Fu, 2013), which provide a reference system that is highly context-dependent and directly correlated with the company's target market characteristics. This highlights a significant difference in the way innovation and export evaluation frameworks are explored in the current literature. Export frameworks are usually market-oriented, while innovation frameworks mainly focus on companies' internal functioning, through practices and processes. 
In a previous work, Enjolras et al. (2016) proposed to fill this gap by providing a framework that includes dimensions, practices and specific observable phenomena simultaneously associated with both innovation and exportation (Figure 3). By using similarity analysis and data spatialization, this research based its framework on the internal practices of SMEs, forming a common space between innovation and export capabilities.

Figure 3: Joint innovation/export framework (Enjolras et al., 2016)

\begin{tabular}{|c|c|}
\hline \multirow[t]{2}{*}{ DIMENSIONS } & JOINT PRACTICES \\
\hline & Defining of a joint strategy innovation/export \\
\hline \multirow[t]{2}{*}{ D1 - Strategy } & Prioritizing projects \\
\hline & Defining a marketing-mix strategy \\
\hline D2 - Intellectual Property & Choosing and Exploiting IP \\
\hline \multirow{2}{*}{ D3-Corporate Culture } & Encouraging autonomy \\
\hline & Fostering information and experiences share \\
\hline \multirow{2}{*}{$\begin{array}{c}\text { D4 - Customer Relationship } \\
\text { Management }\end{array}$} & ManagIng customer relatlonshlp \\
\hline & Involving the customers/users in the project process \\
\hline $\begin{array}{l}\text { D5- Technological and } \\
\text { Commercial Intelligence }\end{array}$ & Researching Information \\
\hline \multirow{2}{*}{ D6 - Networking } & Mobilizing external skills (external providers, institutions...) \\
\hline & Working whithin networks (partners, suppliers, distributors...) \\
\hline \multirow{2}{*}{$\begin{array}{c}\text { D7- Knowledge } \\
\text { Management }\end{array}$} & Storing information \\
\hline & Sharing and Exploiting knowledge \\
\hline \multirow{2}{*}{ D8 - Project Management } & Affecting the material resources (financial, temporal, ...) \\
\hline & Coordinating and planiflying projects (mllestones, costs management...) \\
\hline \multirow{2}{*}{$\begin{array}{c}\text { D9- Human Resources } \\
\text { Management }\end{array}$} & Affecting the human resources (tasks and responsabilities management) \\
\hline & Skills management (training, hiring ) \\
\hline
\end{tabular}

This evaluation makes it possible to understand how the company manages its joint innovation / export practices. By investigating the internal routines of companies, this study is in line with the Schumpeter tradition (Schumpeter, 1934), via the "capability approach" that describes what the company can do and how it seeks to carry out innovation and international activities to ensure continuity over time. From this point of view, the entrepreneur is an actor of change and the enterprise is the result of multiple sources of knowledge that are responsible for carrying out specific routines (Zawislak et al., 2014).
Based on these previous findings, this work uses this theoretical framework as a foundation for an assessment tool measuring SMEs' innovation and export capabilities, highlighting the synergies between their innovation and export practices as a potential driver of development. For that purpose, three methodological steps were defined in order to design a MCDM-based diagnosis (Figure 4). These steps are detailed in the following sections.

Figure 4: Methodological steps
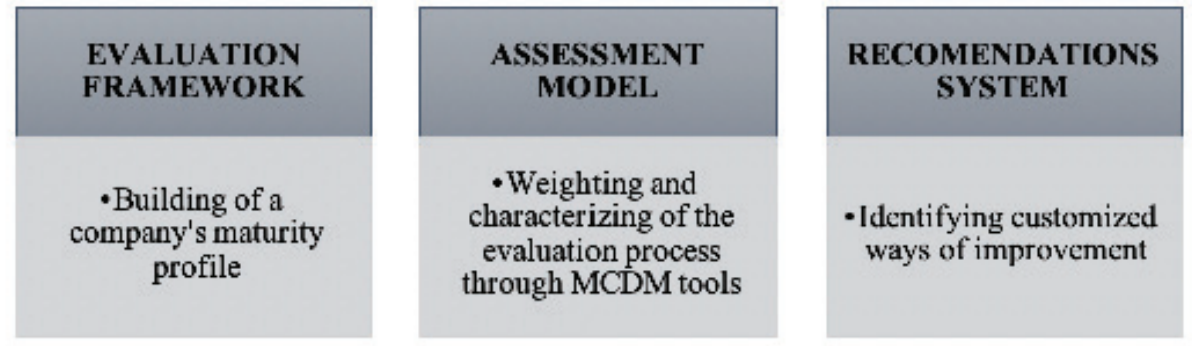


\section{STEP 1: Building of a company's maturity profile}

The first step of the PE2I evaluation is to make a diagnosis of the company's innovation and export capabilities by measuring the degree of maturity of its internal processes. For that purpose, the evaluation relies on a reference table of 17 maturity grids, representing 17 joint innovation/export practices in the chosen theoretical framework (Figure 3).
Maturity grids are regularly used to measure internal processes of organizations (Antunes et al., 2014). According to Andersen et Jessen (2003), the maturity of an organization can be defined as the maximum degree of development, i.e. optimal working conditions, to reach the organization's goals. Maturity grids are thus used to describe, in a progressive and gradual way, the necessary stages to reach a level of maximum development in a considered practice (Table 2).

Table 2. Example of a maturity grid - "Sharing and Exploiting Knowledge" practice

\begin{tabular}{|c|c|c|c|c|}
\hline $\begin{array}{c}\text { Level } 1 \\
\text { Beginner }\end{array}$ & $\begin{array}{c}\text { Level } 2 \\
\text { Amateur }\end{array}$ & $\begin{array}{c}\text { Level } 3 \\
\text { Intermediate }\end{array}$ & $\begin{array}{c}\text { Level } 4 \\
\text { Proficient }\end{array}$ & $\begin{array}{l}\text { Level } 5 \\
\text { Expert }\end{array}$ \\
\hline $\begin{array}{c}\text { Knowledge is not } \\
\text { shared }\end{array}$ & $\begin{array}{l}\text { Knowledge is shared } \\
\text { informally and spon- } \\
\text { taneously }\end{array}$ & $\begin{array}{l}\text { Experts are identified within } \\
\text { the company for their parti- } \\
\text { cular knowledge/know-how. } \\
\text { They are regularly consulted if } \\
\text { necessary. }\end{array}$ & $\begin{array}{l}\text { A procedure for diffusion } \\
\text { and sharing of information } \\
\text { is implemented (interser- } \\
\text { vice meetings, experience } \\
\text { sharing, mailing, training, } \\
\text { etc.). }\end{array}$ & $\begin{array}{l}\text { Digital tools allow information to be shared and } \\
\text { used on a daily basis, at any time and in any pla- } \\
\text { ce. Priority or critical information is identified, } \\
\text { easily accessible and considered with regard } \\
\text { to its impact on the company's strategy. Data } \\
\text { exploitation procedures are implemented. }\end{array}$ \\
\hline
\end{tabular}

In the case of the PE2I, the maturity grids describe 5 progressive levels. Through an interview with the SME's business manager, a score between 1 and 5 is attributed to each of the 17 maturity grids. If the company does not manage the practice properly, its score will be 1 (beginner level) or 2 (amateur level). Conversely, if the company shows good management of the practice, its score will be 4 (proficient level) or 5 (expert level). The evaluation of the degree of maturity relies on descriptive texts serving to identify the situation that corresponds best to the company. These descriptive texts highlight various observable phenomena, which can be defined as tangible and verifiable proofs that a practice is performed routinely within the company (for example, presence of a specific digital tool, formalized data exploitation procedures, meeting reports, etc.). These observable phenomena play the role of indicators allowing an evaluation of the practice. The use of observable phenomena also limits subjectivity in the company evaluation. Each level of the maturity grids is descriptive and could be interpreted differently from one person to another. Levels based on tangible and verifiable proofs reduce this interpretability and make the diagnosis more objective. If these observable phenomena are present within the company and if they can be proved, the practice which they characterize can be considered as mastered.

Based on the 17 scores obtained, an average-based aggregation is realized in order to visualize a global profile of the company according to the 9 joint innovation/export dimensions of the reference framework (Figure 5).

Figure 5: Representation of a company's profile

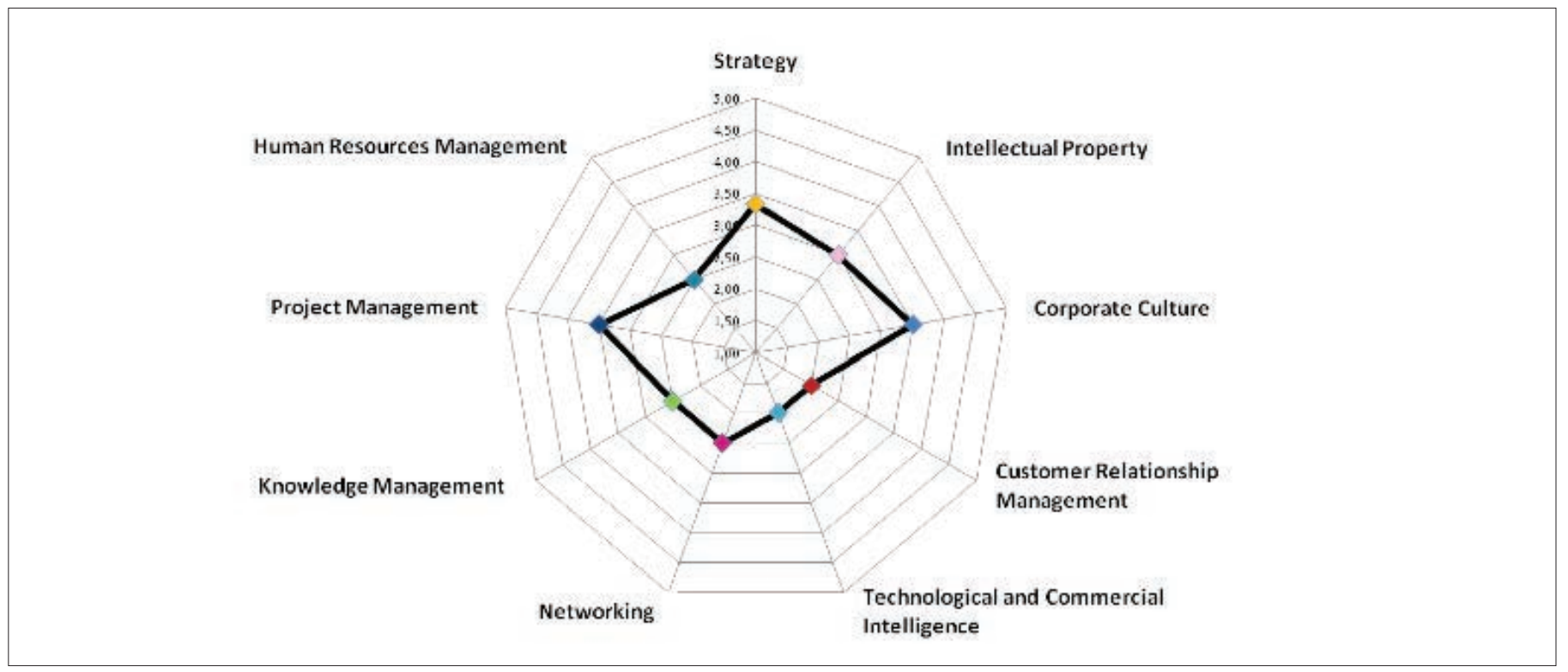

ISSN: 0718-2724. (http://jotmi.org) 
STEP 2: Weighting and characterization of the evaluation process through MCDM tools

The second step of this decision-making tool is to aggregate the maturity scores of the company into a potential innovation and exportation index (PE2I). This aggregation step is based on a combination of two multicriteria analysis methodologies: AHP - Analytic Hierarchy Process (Saaty, 1980) and FlowSort (Nemery and Lamboray, 2007). These two methodologies bring together several parts of the evaluation in order to build a global vision of the potential innovation and exportation capabilities of a company as well as its potential predisposition towards innovation or exports (Figure 6).

Figure 6: Aggregation steps

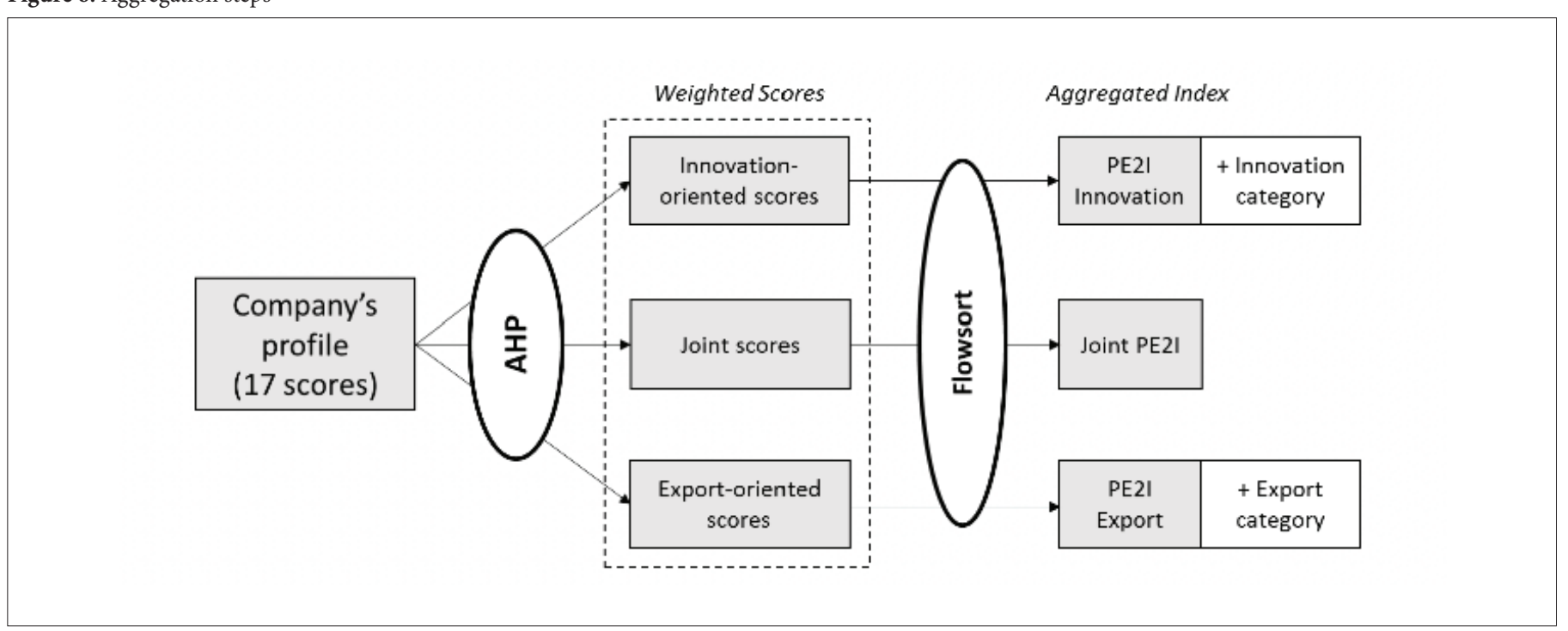

Weighting of activities:

Firstly, AHP was applied in order to propose a weighting of practices, according to their importance in terms of both innovation and export capabilities. Previous works have shown that certain practices have more or less influence on companies' innovation capability (Galvez et al., 2013). Similarly, these same practices are of varying importance in assessing export capacity (Enjolras et al., 2016). Based on this assumption, a differentiated weighting enables a deeper diagnosis by identifying a potential predisposition towards innovation or export. These weights have been defined based on a bibliographic investigation and consultation with experts using AHP. The AHP methodology is based on a principle of pairwise comparison on the basis of expert opinion. It results in a weighting of criteria using the Saaty scale measuring the decision-maker's preference for one criterion over another and by assigning a numerical value to the preference levels. The scale is progressive: value 1 means that both criteria are "equally important" and value 9 means that one criterion is "extremely more important" than the other (Saaty, 2008). The objective is therefore to achieve all combinations of criteria in such a way that they can be compared with each other. For operational reasons, it was decided that practices within the same dimension were equivalent in terms of importance to the calculation of the overall index. Practices belon- ging to the same dimension are therefore equally weighted. The AHP methodology was thus applied only to the first level of aggregation (the 9 dimensions). These comparisons were submitted respectively to experts in innovation and exports. The exportation experts were approached through an online questionnaire in which each expert had to follow the AHP methodology and carry out the Saaty comparisons one by one in order to assess the importance of each dimension in the export activities of companies. The consistency of the 8 responses obtained was checked and all the consistent responses were averaged in order to propose a consensual export-oriented set of weights (Enjolras, 2016). Innovation weighting was based on preliminary research work carried out by (Galvez et al., 2013), using interviews with researchers and institutions specializing in innovation in the form of a focus group. This enabled an assessment of the importance of each practice for companies' innovation activities. This double-expert confrontation finally provided 2 sets of weights: innovation-oriented and export-oriented. A joint weighting was also built, based on the average of the other two (Table 3). The proposition of three different weights avoids a compensation effect linked to an average calculation. The joint weighting provides an overall view of the relative importance of each practice, but the export-oriented and innovation-oriented weightings bring nuance by highlighting a potential predisposition of companies either towards innovation or towards exports. 
Table 3: Dimensions / Practices weighting

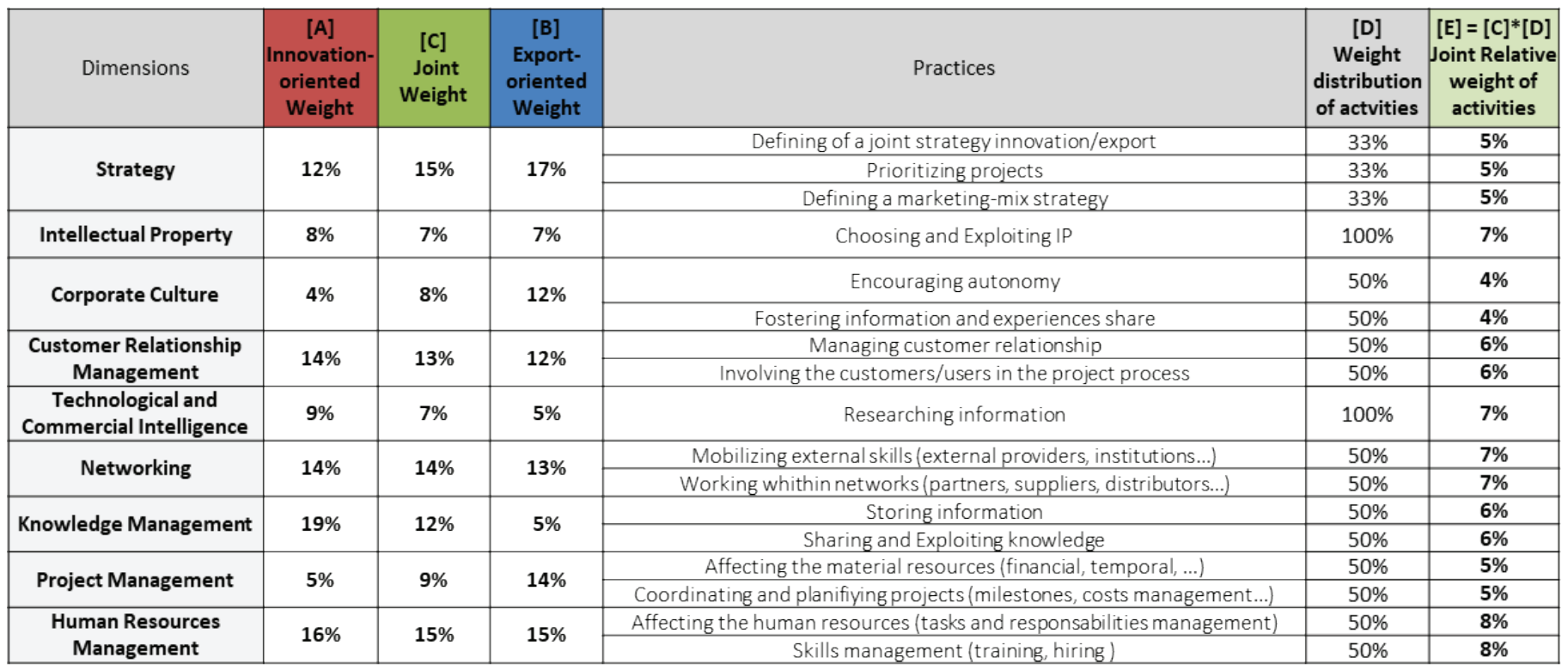

These results show that practices with an equivalent and relatively high weighting from both an innovation and an exportation point of view concern strategy, customer relationship management, networking and human resources management. Practices with a high weighting in terms of innovation and a low weighting in terms of exports mainly concern knowledge management. Conversely, practices that are essential for exports and secondary for innovation concern corporate culture and project management. Finally, practices with an average or low weighting in both innovation and exports correspond to intellectual property management and commercial/technological intelligence. In view of the results obtained, it seems that the most important dimensions impacting upon innovation relate to an openness towards knowledge and its exploitation, while those impacting upon exports favor changes in internal functioning and culture.

\section{Calculation of a global index and sorting process:}

Finally, a sorting method was used to provide a global index that aggregates evaluations of each company's practices and classifies them into a category that reflects its behavior profile in terms of innovation (Passive/ Reactive/ Reactive/ Preactive/ Proactive) and exports (Stayat-home/ Traveler/ Explorer/ Adventurer) (Figure 7).

FlowSort was chosen. This method is a direct extension of Promethee, which is based on a flow calculation. A particularity of FlowSort is that unlike Electre-Tri, the most widely used sorting method (Ishizaka and Nemery, 2013), the assignment of an evaluation to a category depends on an overall comparison with all the boundary profiles of the categories simultaneously. Indeed, FlowSort deals with a sorting problem through a ranking method which is therefore applied to all the data, consisting of both evaluations and reference profiles. The category will then be deduced from the relative position of the evaluation in relation to the reference profiles in the ranking obtained (Nemery and Lamboray, 2007). FlowSort therefore proposes a global approach by proposing a comparison with all the limit profiles and is based on a well-known ranking methodology, Promethee. It provides a classification of companies according to categories (defined by limit profiles) relying on a flow calculation leading to an aggregated index: PE2I.

Figure 7: PE2I aggregation - example

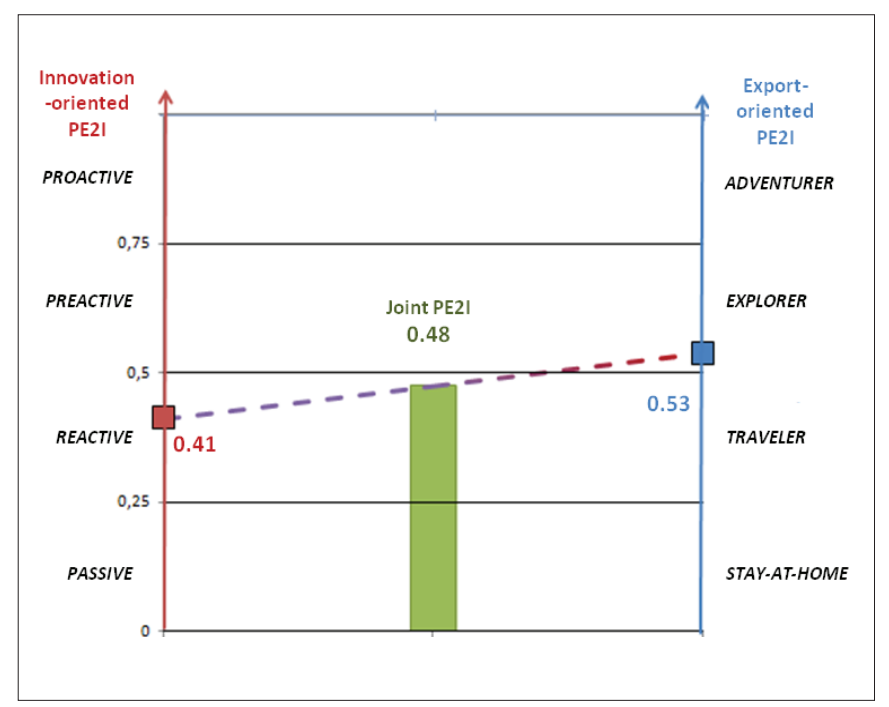

The 4 categories describing the innovation profile of companies show the innovation dynamics of the companies and their attitude to novelty. Passive ones have a very low innovation capability and are mainly oriented towards an adaptation dynamic. Proactive ones have a longterm vision, adopting a voluntarist strategy and an anticipative attitude (Godet, 1997). 
Similarly, the categories describing the export-oriented profile are:

i. $\quad$ Stay-at-home: Companies exporting in a very irregular way, generally by opportunity. They target close markets (both culturally and geographically) in order to limit risk.

ii. Traveler: Companies exporting regularly but limited to close and reassuring countries.

iii. Explorer: Companies for which export sales represent an important part of their turnover. They export in a regular and intensive way towards easily accessible countries and also target more distant countries.

iv. Adventurer: Companies for which exporting is second nature. Geographical and cultural distance does not pose any problem. They export in a continuous and intensive way towards markets that are known for being difficult to access.
In order to illustrate the scope of the proposed methodology regarding the definition of a strategy, let us imagine that the results shown in Figure 7 belong to a hypothetical firm. The evaluated company displays a medium joint innovation/export capability (joint PE2I $=0.48$ ), but it clearly seems that this company has a predisposition towards exports. Its export-oriented PE2I (0.53) is higher than its innovation-oriented PE2I (0.41). This means that this company masters practices that are very important for export, rather than those that are important for innovation. In this case, this difference is particularly marked because the company belongs to the "Explorer" category for exports (3rd category), and to the "Reactive" category for innovation (2nd category).

\section{STEP 3: Identifying customized ways of improvement}

Based on the company's profile and on its PE2I indexes, customized recommendations can be proposed in order to improve its innovation and export capabilities. The identification of weaknesses confronted with the potential predispositions of companies, as well as with their strategy, allow the definition of a progress plan which is as realistic as possible. Three standard improvement strategies were identified: a scenario favoring innovation, a scenario favoring export development, and finally a joint scenario (Figure 8).

Figure 8: Comparison of the improvement scenarios

Do you want to favor Innovation?
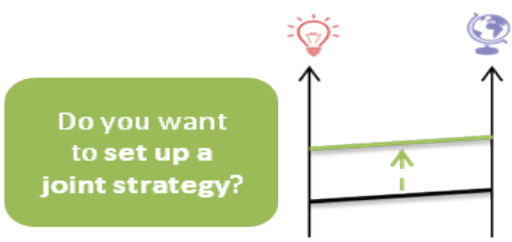

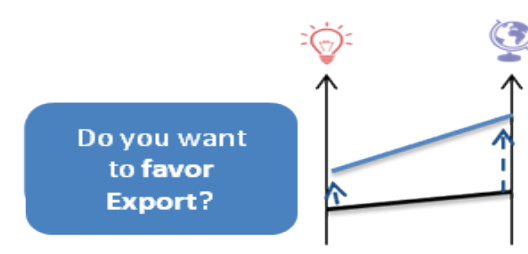

The first scenario consists in choosing an orientation towards innovation. This scenario seeks to improve the degree of maturity in practices that are of great importance to the company's innovation capability. The objective is to identify, among the weak points of the evaluated company, the practices that are particularly important for innovation and to encourage the company to improve them first and foremost. These innovation-oriented practices mainly concern knowledge management, customer relationship, network and human resources management (see innovation-oriented weighting - Table 3). Through this scenario, the company simultaneously improves its innovation capability and its export capability, but it favors innovation. This improvement scenario can be applied, for example, to a company that shows a strong predisposition towards exports and wishes to rebalance its profile by improving innovation. This scenario can also be applied to a very innovative company wishing to strengthen this strategic positioning while improving, to a lesser extent, its export capacity.
The second scenario consists in choosing an orientation towards exports. This scenario aims at improving practices that are particularly important for exports: Strategy, human resources management, project management and networking (See export-oriented weighting Table 3). By choosing this scenario, the company simultaneously improves its innovation capability and its export capability, but it gives a priority to exports. This scenario can be applied, among others, to a young exporting company looking to introduce or to strengthen its international development.

The third scenario consists in choosing a strategy of joint innovation / export improvement. This scenario proposes to act first and foremost on practices that are important for export and innovation at the same time. These synergistic practices concern mainly strategy, human resources management, networking and customer relations. This scenario is suitable, for example, for companies with very few resources and that have a rather low evaluation. By choosing this scenario, they can progress in both areas by optimizing their mobilization of resources. 


\section{Case study: Application of the PE2I diagnosis to a French manufacturing SME}

The PE2I was tested through a case study presenting the evaluation of a French industrial SME. The purpose of this application was to test the functioning of the PE2I in a real situation, as well as to validate the relevance of its results by confronting them with the company directors' vision.

\section{Methodology}

The case study was conducted in the form of a semi-directive interview lasting approximatively 2 hours. The first part of the interview was dedicated to the company's evaluation through the PE2I methodology. Further to a short presentation of the context of our study, a discussion with the business manager led to the evaluation of the maturity level of the company in joint innovation/export practices. A score between 1 and 5, corresponding to the level of the associated maturity grid, was attributed to each practice in order to obtain the company's profile. A first discussion phase was then introduced to explain the results obtained. Further to the presentation of the company's profile, one (or several) scenario (s) of improvement could be chosen by the business manager. Recommendations were then formulated and discussed in the form of feedback. Finally, a recapitulative report was drafted and sent by e-mail to the company. This report contains the detailed results obtained during the interview: the company's profile as well as the means of improvement envisaged according to one or several scenario(s) chosen.

\section{Results: Company X diagnosis}

Company $\mathrm{X}$ is an SME with approximately 200 employees in the field of medium-high technology (according to the industry classification proposed by the OECD (Hatzichronoglou, 1997)). It makes 6\% of its turnover in exports and has significant R\&D activity. It is currently initiating development of its activity towards a market in South America renowned as protectionist and is encountering some difficulties cracking this market.

Figure 9: Company X's profile

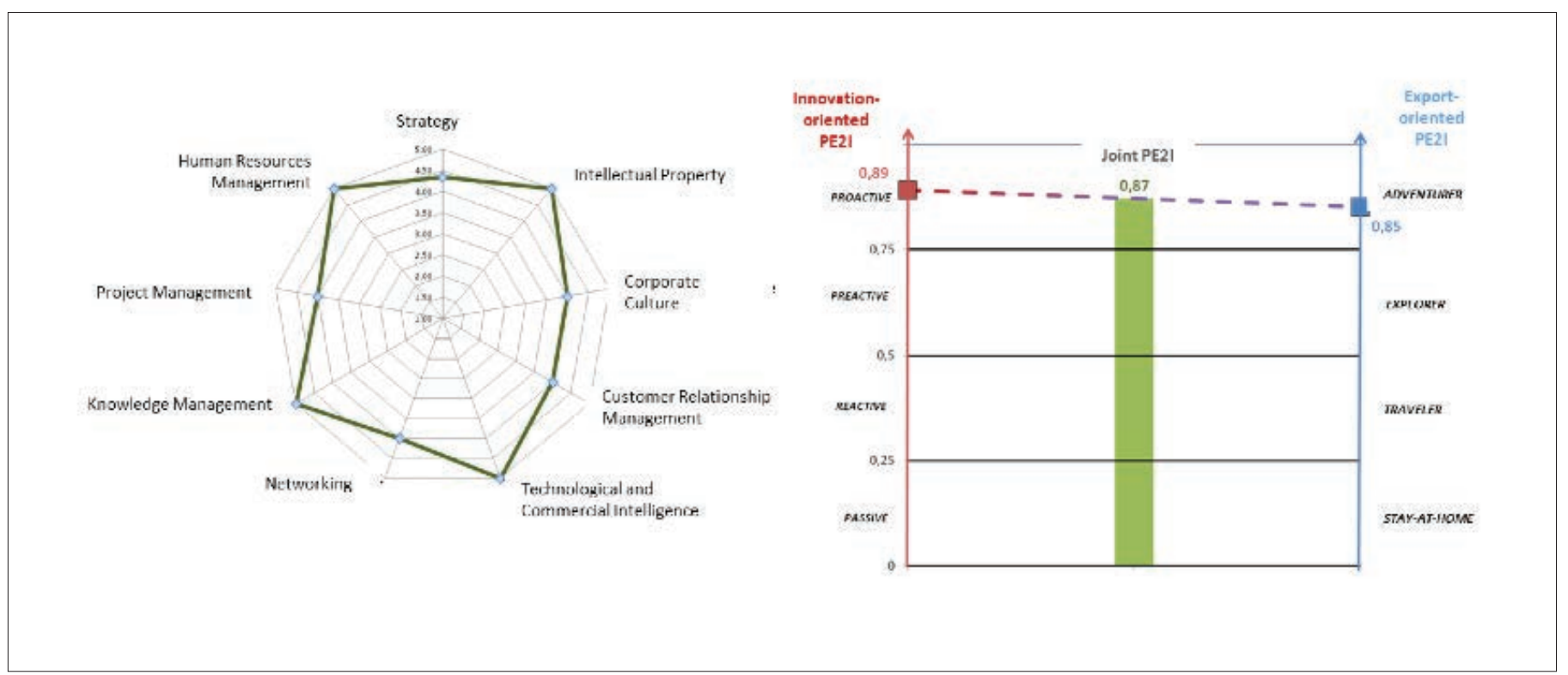

Company X displays a successful and well-balanced profile. Its evaluation according to the set of 9 joint innovation / export dimensions is relatively uniform. Figure 9 shows that company $\mathrm{X}$ has a high joint PE2I Index (0.87) and it seems to have a clear predisposition towards innovation (its innovation-oriented PE2I is higher than its export-oriented PE2I). This company is classified in the highest category in terms of both innovation (Proactive) and export (Adventurer). This result seems coherent, because company $\mathrm{X}$ has a strong $\mathrm{R} \& \mathrm{D}$ activity associated with a long-term vision on the one hand, and significant development of its export activities on the other hand.
Its key strengths seem to be technological and commercial intelligence, intellectual property, knowledge management and human resources management. These capabilities are clearly proof of a voluntarist and anticipative strategy, which is characteristic of proactive companies. Concerning exports, Company $\mathrm{X}$ has planned to develop distant and difficult markets. According to the evaluation, this company seems able to manage difficulties associated with its development project, although some improvements can be envisaged.

\section{Scenario of improvement $n^{\circ} 1$ : favoring export}

Company $\mathrm{X}$ chose to first visualize the improvement scenario favoring export (Figure 10), in line with its short / medium term strategy. 
Figure 10: Potential improvement for company $\mathrm{X}$ according to the export-oriented scenario

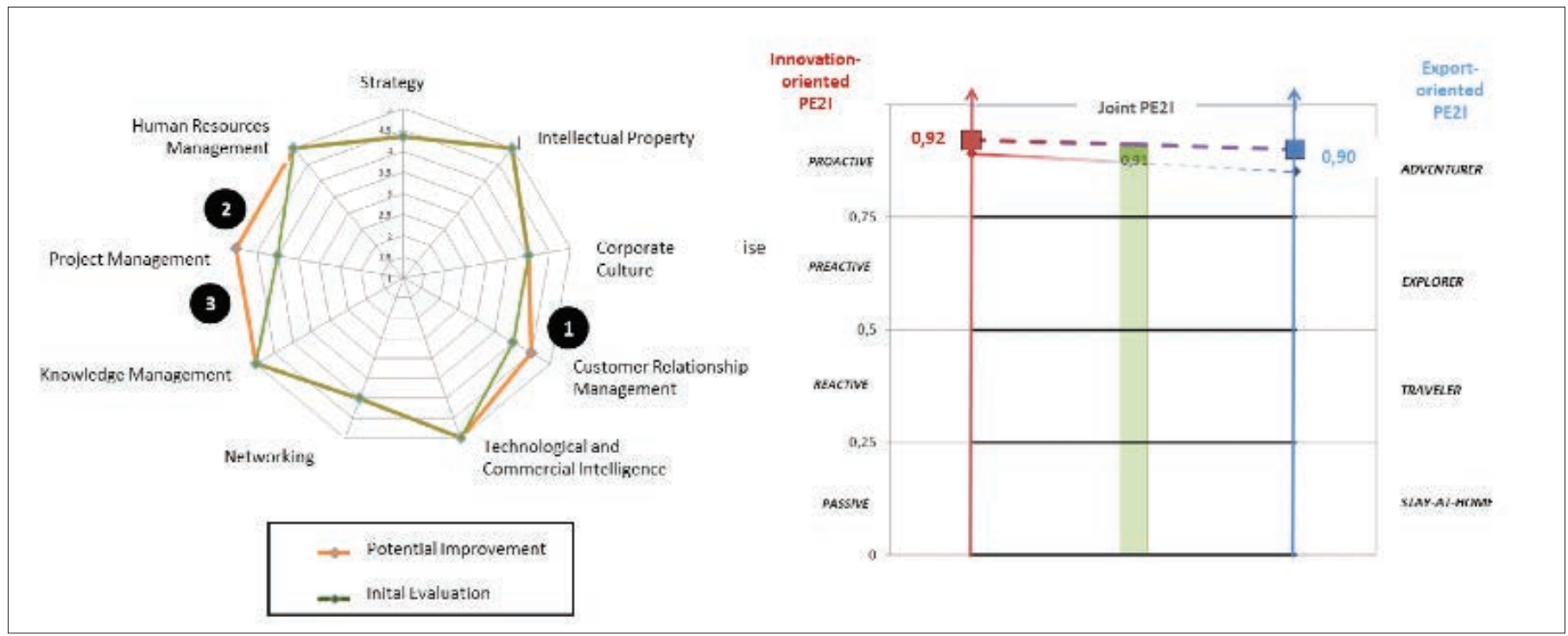

The first critical practice identified concerns customer relations. The recommendation associated with this practice is to strengthen the involvement of the customer/user in the project management process. The second and third critical practices concern project management and more particularly resource allocation, as well as project planning. Customer involvement reduces the risks related to product acceptability in risky overseas markets. Project management improvement reduces the organizational risks related to exports in distant markets (both geographically and culturally). This first result highlights that these improvements are related to internal actions within the company in order to formalize and secure its exporting process.

\section{Scenario of improvement $n^{\circ} 2$ : Joint innovation/export improvement}

The second scenario chosen by Company $\mathrm{X}$ is to put in place a joint innovation/export improvement action (Figure 11). Similarly, to the export-oriented scenario, the first critical practice identified concerns the involvement of customers in the project process. However, the second and third critical practices concern networking: close networks (suppliers, partners, distributors, etc.) and external skills (providers, jurists, etc.). For company X's project, the development of its network seems to be an appropriate recommendation because international development on risky markets can be supported by the formation of partnerships and requires a reliable selection of distributors. Additionally, these recommendations improve the innovation capability of Company X and lead to a potential differentiating position compared to its competitors on the targeted markets. So, the joint scenario fosters the acquisition of a competitive advantage through openness to potential partnerships as well as to potential foreign customers. We thus observe a strong strategic difference with the previous scenario of improvement, which favors exports through the formalization and structuring of the company.

Figure 11: Potential improvement for company $\mathrm{X}$ according to the joint scenario

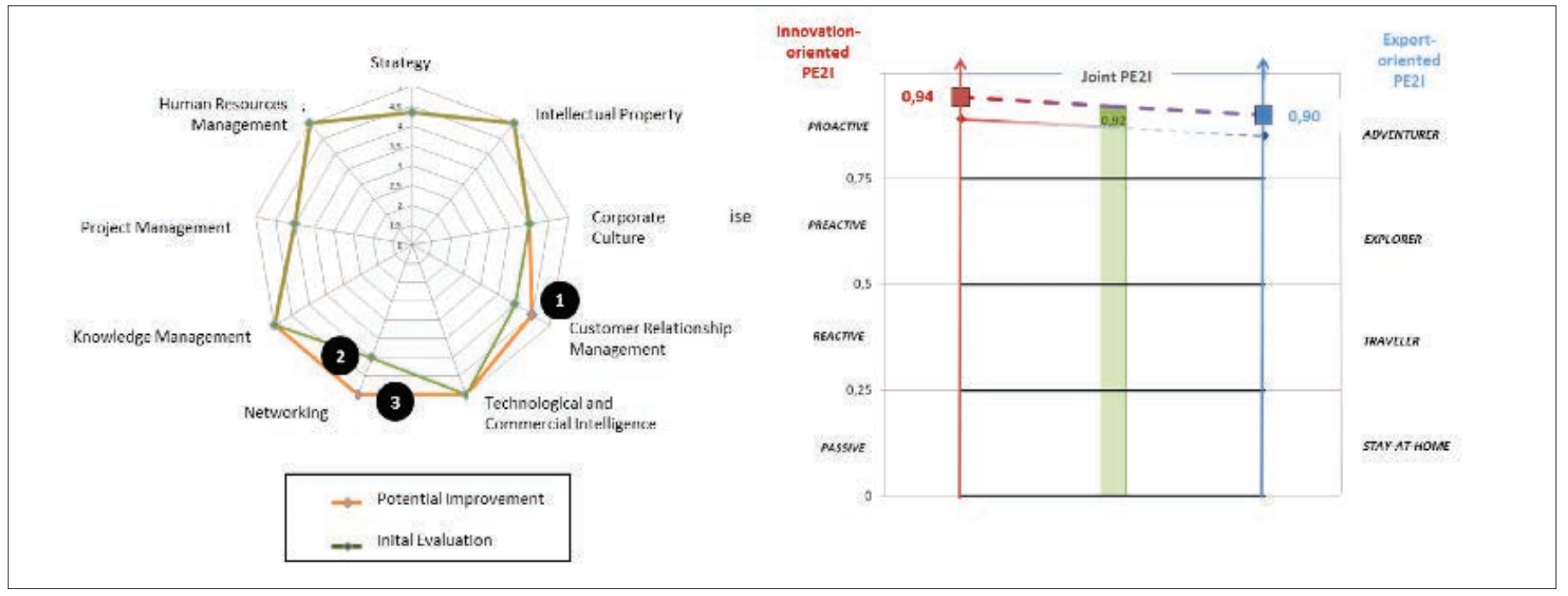




\section{Discussion}

The results given by the PE2I allow Company $\mathrm{X}$ to reflect upon its priority: favoring the acquisition of a competitive advantage (joint scenario) or ensuring the formalization of the company's internal processes (export-oriented scenario). As a decision support tool, the PE2I diagnosis proposes 2 possible means of improvement through a modelling of the company's situation, but it is up to the business leader to decide by making an objective and informed decision. To support this decision process, the automatic and immediate calculation of results appears to be a facilitator, both in making the diagnosis and building suitable recommendations.

The application of the PE2I to Company X displays several limits. First of all, it should be underlined that an interlocutor was essential to interpret the diagnosis results. This type of tool requires good knowledge of its operational functioning in order to derive the relevant information. Next, the tool relies on a hypothesis according to which the formalization and structuring of innovation and export practices within companies improve their innovation and exportation capabilities. However, in the literature there are few empirical studies confirming this assumption and it is difficult to find a consensus. Although their practices are different from those of large companies, certain SMEs do plan, formalize and structure their internal organization (Goy and Paturel, 2004). A study by García Pérez de Lema et al. (2012) on a sample of 1000 Spanish SMEs reveals that SMEs using formalization and strategic planning tools are more successful than others. These results also show that the structuring of SMEs increases, among others, with the size and the age of the company, its technological intensity and the level of qualifications of its leader. On the other hand, certain SMEs compensate for their lack of formalization by functioning intuitively, based on a long-term and anticipative vision (Sauner-Leroy, 2000). Furthermore, in the particular case of very small structures, formalization does not always seem necessary in view of their compact spatial configuration (Torrès, 2015). Encouraging SMEs to formalize and structure their internal processes, regardless of their functioning mode and their characteristics, could therefore be a limitation of the PE2I. In the same way, a problem of adaptability may arise. Indeed, each company presents specificities related either to its business sector, its structure, its environment, or to its own strategic positioning (Mintzberg, 1979). The relevance of intellectual property, project or customer relations management are problems which may require a customized evaluation. Therefore, modifying the structure of the PE2I to make it more adaptable could be a perspective for further work, in order to take into account determining factors such as firms' specificities, contextual elements or strategic orientations. For example, the context of Company X makes the formalization of project management difficult because very few products are made every year, and their quantity is highly variable. The export-oriented scenario proposed by the PE2I does not really seem suited to this specific context, while the joint scenario of improvement makes more sense for the business leader. In this case, the choice of scenario does not depend on a strategic decision, but on a contextual constraint.
Nevertheless, the empirical application of this diagnosis tool produced interesting feedback from the users, i.e. company managers. The PE2I appears to be a tool for representing and formalizing concepts often known to the manager, but not formalized. Thus, the discovery of the company's profile, its strengths and weaknesses did not necessarily come as a surprise to the manager, but the tool structured them and connected them to each other. On several occasions the pedagogical effect of the tool was underlined, in particular because it objectified tacit knowledge or feelings. The manager received an unbiased model of the company's situation and could then base his or her decisions on it. This feedback related mainly to the automation of the data processing necessary to visualize the company's profile and to identify means of improvement. The interactive and factual nature of the PE2I leads companies to reflect upon their own functioning. It acts as a real decision-making support, putting the business leader at the heart of an interactive evaluation/decision process.

\section{Conclusion}

This paper presents a new methodology for evaluating SMEs' innovation and export capabilities: the PE2I tool. This diagnosis tool proposes a joint and complementary vision of innovation and exports through the characterization of a common space using MCDM methodologies. The objective of this tool is to provide a decision-making support enabling managers to identify key factors (strengths and weaknesses) in order to design a balanced strategy to simultaneously reinforce the firm's innovation and export capabilities. It encourages SMEs to act first and foremost on internal practices, creating synergies and minimizing the effort associated with improving their performance. The PE2I provides an overview of the company's situation so as to highlight its strengths and its weaknesses. From this overview, it proposes customized means of improvement according to the company's profile and its development strategy.

The main scientific contribution of this research is first of all the systemic vision that it provides of the innovation / export relationship in SMEs. While traditionally this relationship is considered as causal, this work proposes to envisage it through the prism of complementarity. This systemic vision is then supported by a methodological contribution: a combined AHP-Flowsort MCDM methodology to model the complexity associated with the decision-making process in innovation/export management within SMEs. It represents a contribution to the scientific literature because, by proposing a pragmatic tool, it aims at operationalizing a relationship that is mostly studied in a theoretical way. Finally, an empirical contribution is proposed through the application of this tool within a French company.

However, certain development perspectives should be envisaged. Although this research highlights findings based of a case study approach, some potential theoretical and methodological improvements need to be pointed out to make it generalizable. With the aim of making the tool more flexible, it seems first of all worth adapting it to the contextual factors of companies, such as business sector, size, technological intensity (Enjolras et al., 2019), etc. For that purpose, 
the first stage would be to identify sets of weightings for dimensions and activities according to the contextual factors considered. For example, industrial property management could potentially have a lower weighting for a company in the IT sector, while it seems more important for businesses working in mechanics. This variation in weightings could lead to a more customized evaluation and more relevant recommendations, but it requires numerous tests and validations so as to obtain statistically representative data for every business sector considered.

Concerning the bias to encourage companies to formalize their internal processes, a series of applications would validate or otherwise the relevance of the tool. It would be interesting to test qualitatively whether the reservation about the structuring and formalization of certain internal practices is repeated significantly or not; and if this is the case, what moderating variables need to be considered: age, size, technological profile, profile of the business leader, etc.

In line with these research perspectives and managerial applications, a dedicated research program was launched in September 2018. Through this research program, ${ }^{2}$ we propose to progressively shift from the experimental stage (identification of synergistic effects put into practice) to the large-scale development of a pragmatic diagnostic tool that can be deployed in development agencies to assess the capacities that an SME has or must develop as a priority to simultaneously improve its innovation and export performances. Based on this diagnostic framework, several additional empirical studies can be considered. First, a sectoral analysis could be carried out in order to identify specificities or differentiating factors in terms of SMEs' internal practices. Secondly, longitudinal studies could be initiated in order to visualize the evolution of companies' innovation and export capabilities over time.

\section{Acknowledgements}

We would like to thank to company X for its participation in our study. This work was supported partly by the French PIA project "Lorraine Université d'Excellence", reference ANR-15-IDEX-04-LUE.

\section{References}

Andersen, E.S., Jessen, S.A., 2003. Project maturity in organisations. International Journal of Project Management, Selected papers from the Fifth Biennial Conference of the International Research Network for Organizing by Projects. Held in Renesse, Seeland, The Netherlands, 28-31 May 2002. 21, 457-461. https://doi.org/10.1016/S02637863(02)00088-1

Angela, G., Athanasios, B., Konstantinos, R., 2015. Export Success Factors for Table Olives: The Perception of Greek Exporting Firms. Procedia Economics and Finance, The Economies of Balkan and Eastern Europe Countries in the Changed World (EBEEC 2015) 33, 584-594. https://doi.org/10.1016/S2212-5671(15)01740-2
Antunes, P., Carreira, P., Mira da Silva, M., 2014. Towards an energy management maturity model. Energy Policy 73, 803-814. https://doi. org/10.1016/j.enpol.2014.06.011

Ayllon, S., Radicic, D., 2019. Product innovation, process innovation and export propensity: persistence, complementarities and feedback effects in Spanish firms. Applied Economics 51, 3650-3664. https:// doi.org/10.1080/00036846.2019.1584376

Biemans, W., Griffin, A., 2018. Innovation practices of B2B manufacturers and service providers: Are they really different? Industrial Marketing Management 75, 112-124. https://doi.org/10.1016/j.indmarman.2018.04.008

Bołkunow, W., 2019. Internationalization of European Small and Medium-Sized Companies, in: Bilgin, M.H., Danis, H., Demir, E., Can, U. (Eds.), Eurasian Business Perspectives, Eurasian Studies in Business and Economics. Springer International Publishing, pp. 39-51.

Boly, V., Morel, L., Assielou, N.G., Camargo, M., 2014. Evaluating innovative processes in french firms: Methodological proposition for firm innovation capacity evaluation. Research Policy 43, 608-622. https://doi.org/10.1016/j.respol.2013.09.005

Boso, N., Story, V.M., Cadogan, J.W., Micevski, M., Kadić-Maglajlić, S., 2013. Firm Innovativeness and Export Performance: Environmental, Networking, and Structural Contingencies. Journal of International Marketing 21, 62-87. https://doi.org/10.1509/jim.13.0052

Castro Silva, Ana Cristina G., Cristiano Hora de O. Fontes, and Ava Santana Barbosa. 2015. "Multicriteria Evaluation Model for Organizational Performance Management Applied to the Polo Fruit Exporter of the São Francisco Valley." Computers and Electronics in Agriculture 117: 168-76.

Chen, T., Chen, X., Wang, C., Xiang, X., 2018. Export behavior and firm innovation: New method and evidence. Economics Letters 170, 76-78. https://doi.org/10.1016/j.econlet.2018.05.029

Chiadamrong, N., and Kawtummachai R. 2008. "A Methodology to Support Decision-Making on Sugar Distribution for Export Channel: A Case Study of Thai Sugar Industry." Computers and Electronics in Agriculture 64(2): 248-61.

Dahooie, J. H. et al. 2020. "Development of a Firm Export Performance Measurement Model Using a Hybrid Multi-Attribute DecisionMaking Method." Management Decision.

Dai, M., Liu, H., Lin, L., 2019. How innovation impacts firms' export survival: Does export mode matter? World Economics https://doi. org/10.1111/twec. 12847

Di Cintio, M., Ghosh, S., Grassi, E., 2019. Direct or indirect exports: what matters for firms' innovation activities? Applied Economics Letters https://doi.org/10.1080/13504851.2019.1610693

(2) Innov4SME project: https:/erpi.univ-lorraine.fr/projects/Inov4SME/

Diagnosis: https://diagnostic.innovation-way.com/ 
Enjolras, M., Camargo, M., and Schmitt C., 2019. "Are High-Tech Companies More Competitive Than Others? An Empirical Study of Innovative and Exporting French SMEs." Technology Innovation Management Review 9 (1): 33-48. https://doi.org/http://doi. org/10.22215/timreview/1210.

Enjolras M., 2016. Méthodologie d'analyse de la capacité à innover et à exporter des PME manufacturières et de procédés : Identification et caractérisation d'un espace commun en vue de l'élaboration d'un outil multicritères d'aide à la décision (Thèse de doctorat). Université de Lorraine, Nancy, France.

Enjolras M., Camargo M., Schmitt C., 2016. SMEs' Innovation and Export Capabilities: Identification and Characterization of a Common Space Using Data Spatialization. Journal of technology management \& innovation 11, 56-69. https://doi.org/10.4067/S071827242016000200006

European Commission, 2007. Supporting the internationalisation of SMEs (Final Report of the Expert Group). Entrepreneurship Unit, Directorate-General for Enterprise and Industry.

European Commission, 2018. Annual report on European SMEs 2017/2018 : Special Background Document on the Internationalisation of SMEs (SME Performance Review 2017 / 2018).

Fassio, C., 2018. Export-led innovation: the role of export destinations. Industrial and Corporate Change 27, 149-171. https://doi. org/10.1093/icc/dtx028

FedEx corp., 2015. European SME Export Report - Export /Import trends and behaviours of SMEs in Europe. FedEx Express.

Galvez, D., Camargo, M., Rodriguez, J., Morel, L., 2013. PII- Potential Innovation Index: a Tool to Benchmark Innovation Capabilities in International Context. Journal of Technology Management \& Innovation $8,36-45$.

García Pérez de Lema, D., Trejo, V.G.S., Bárcenas, R.E., 2012. Facteurs caractéristiques de la planification stratégique dans la PMI : une étude empirique sur des entreprises en Espagne. Recherches en Sciences de Gestion 19-33.

Gkypali, A., Arvanitis, S., Tsekouras, K., 2018. Absorptive capacity, exporting activities, innovation openness and innovation performance: A SEM approach towards a unifying framework. Technological Forecasting and Social Change 132, 143-155. https://doi.org/10.1016/j. techfore.2018.01.025

Godet, M., 1997. Manuel de prospective stratégique. Dunod, Paris.

Golovko, E., Valentini, G., 2014. Selective Learning-by-Exporting: Firm Size and Product Versus Process Innovation. Global Strategy Journal 4, 161-180. https://doi.org/10.1002/gsj.1080
Golovko, E., Valentini, G., 2011. Exploring the complementarity between innovation and export for SMEs growth. Journal of International Business Studies 42, 362-380.

Goy, H., Paturel, R., 2004. Les problématiques de diagnostic et de projection dans les PMI. Revue française de gestion no 150, 55-70.

Halilem, N., Amara, N., Landry, R., 2014. Exploring the relationships between innovation and internationalization of small and medium-sized enterprises: A nonrecursive structural equation model. Canadian Journal of Administrative Sciences 31, 18-34. https://doi. org/10.1002/cjas.1272

Hatzichronoglou, T., 1997. Révision des classifications des secteurs et produits de haute technologie, Editions OCDE.

Ishizaka, A., Nemery, P., 2013. Multi-criteria Decision Analysis: Methods and Software. Wiley-Blackwell, Chichester, West Sussex, United Kingdom.

Kafouros, M.I., Buckley, P.J., Sharp, J.A., Wang, C., 2008. The role of internationalization in explaining innovation performance. Technovation 28, 63-74. https://doi.org/10.1016/j.technovation.2007.07.009

Kahiya, E.T., 2018. Five decades of research on export barriers: Review and future directions. International Business Review 27, 1172 1188. https://doi.org/10.1016/j.ibusrev.2018.04.008

Korhonen, P., Moskowitz, H., Wallenius, J., 1992. Multiple criteria decision support - A review. European Journal of Operational Research 63, 361-375. https://doi.org/10.1016/0377-2217(92)90155-3

Kurka, T., Blackwood, D., 2013. Selection of MCA methods to support decision making for renewable energy developments. Renewable and Sustainable Energy Reviews 27, 225-233. https://doi.org/10.1016/j. rser.2013.07.001

Leonidou, E., Christofi, M., Vrontis, D., Thrassou, A., 2018. An integrative framework of stakeholder engagement for innovation management and entrepreneurship development. Journal of Business Research. https://doi.org/10.1016/j.jbusres.2018.11.054

Love, J.H., Roper, S., 2015. SME innovation, exporting and growth: A review of existing evidence. International Small Business Journal 33, 28-48. https://doi.org/10.1177/0266242614550190

Mintzberg, H., 1979. The Structuring of Organizations. Pearson, Englewood Cliffs, N.J.

Moeuf, A., Pellerin R., Lamouri S., Tamayo-Giraldo S., and Barbaray R. 2018. "The Industrial Management of SMEs in the Era of Industry 4.0." International Journal of Production Research 56 (3): 1118-36. https://doi.org/10.1080/00207543.2017.1372647. 
Monreal-Pérez, J., Aragón-Sánchez, A., Sánchez-Marín, G., 2012. A longitudinal study of the relationship between export activity and innovation in the Spanish firm: The moderating role of productivity. International Business Review 21, 862-877. https://doi.org/10.1016/j. ibusrev.2011.09.010

Nemery, P., Lamboray, C., 2007. FlowSort: a flow-based sorting method with limiting or central profiles. TOP 16, 90-113. https://doi. org/10.1007/s11750-007-0036-x

OECD, 2009. Top Barriers and Drivers to SME Internationalisation. Working Party on SMEs and Entrepreneurship.

OECD, 2018. Oslo Manual.

Okreglicka, M., Gorzen-Mitka, I., Ogrean, C., 2015. Management challenges in the context of a complex view - SMEs perspective, in: Sujova, A., Krajcirova, L. (Eds.), International Scientific Conference: Business Economics and Management (Bem2015). Elsevier Science Bv, Amsterdam, pp. 445-452.

Pla-Barber, J., Alegre, J., 2007. Analysing the link between export intensity, innovation and firm size in a science-based industry. International Business Review 16, 275-293. https://doi.org/10.1016/j. ibusrev.2007.02.005

Ribau, C.P., Moreira, A.C., Raposo, M., 2019. The role of exploitative and exploratory innovation in export performance: an analysis of plastics industry SMEs. European Journal of International Management 13, 224-246. https://doi.org/10.1504/EJIM.2019.098149

Roper, S., Love, J.H., 2002. Innovation and export performance: evidence from the UK and German manufacturing plants. Research Policy 31, 1087-1102. https://doi.org/10.1016/S0048-7333(01)00175-5

Saaty, T.L., 2008. Decision making with the analytic hierarchy process. International Journal of Services Sciences 1, 83-98. https://doi. org/10.1504/IJSSci.2008.01759

Saaty, T.L., 1980. The Analytic Hierarchy Process: Planning, Priority Setting, Resource Allocation. McGraw-Hill.
Sauner-Leroy, J.-B., 2000. Nature de l'environnement, style de direction et performance des firmes: un test de la théorie de la contingence, in: Perspectives En Management Stratégique. Presented at the IXème conférence internationale de management stratégique, Montpellier, France.

Schmitt, C., Julien, P.-A., Lachance, R., 2002. Pour une lecture des problèmes complexes en PME: approche conceptuelle et expérimentation. Revue internationale P.M.E. : Économie et gestion de la petite et moyenne entreprise 15, 35-62. https://doi.org/10.7202/1008806ar

Schumpeter, J.A., 1934. The Theory of Economic Development: An Inquiry Into Profits, Capital, Credit, Interest, and the Business Cycle. Transaction Publishers.

Seens, D., 2015. SME profile: Canadian exporters. Industry Canada Small Business Branch - Research and Analysis Directorate.

Szczepanski, M., 2016. Barriers to SME growth in Europe. European Parliamentary Research Service.

Torrès, O., 2015. Petitesse des entreprises et grossissement des effets de proximité. Rev. Fr. Gest. 41, 333-352. https://doi.org/10.3166/ RFG.144.119-138

Torrès, O., and Julien, P. A., 2005. "Specificity and Denaturing of Small Business." International Small Business Journal 23 (4): 355-77. https://doi.org/10.1177/0266242605054049.

Zawislak, P.A., Gamarra, J.T., Alves, A.C., Barbieux, D., Reichert, F.M., 2014. The different innovation capabilities of the firm: further remarks upon the Brazilian experience. Journal of Innovation Economics \& Management 129-150.

Zehir, C., Köle, M., Yıldız, H., 2015. The Mediating Role of Innovation Capability on Market Orientation and Export Performance: An Implementation on SMEs in Turkey. Procedia - Social and Behavioral Sciences, 11th International Strategic Management Conference 207, 700-708. https://doi.org/10.1016/j.sbspro.2015.10.141

Zhu, S., Fu, X., 2013. Drivers of Export Upgrading. World Development 51, 221-233. https://doi.org/10.1016/j.worlddev.2013.05.017 
